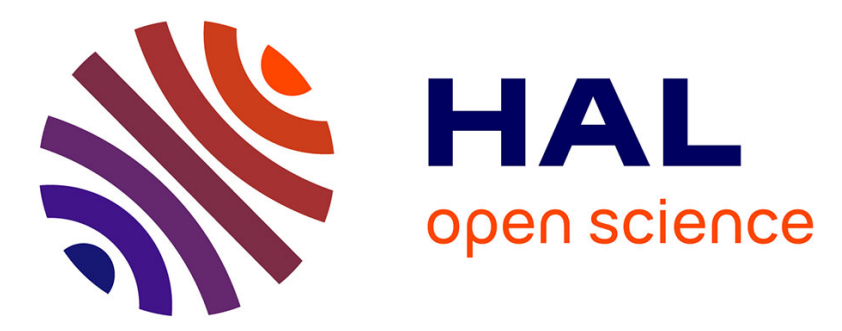

\title{
Tensile stress effect on magnetic properties of cw-laser annealed amorphous Fe40Ni40P14B6 ribbons
}

L. Lanotte

\section{To cite this version:}

L. Lanotte. Tensile stress effect on magnetic properties of cw-laser annealed amorphous Fe40Ni40P14B6 ribbons. Journal de Physique Lettres, 1983, 44 (13), pp.541-546. 10.1051/jphyslet:019830044013054100 . jpa-00232229

\section{HAL Id: jpa-00232229 https://hal.science/jpa-00232229}

Submitted on 1 Jan 1983

HAL is a multi-disciplinary open access archive for the deposit and dissemination of scientific research documents, whether they are published or not. The documents may come from teaching and research institutions in France or abroad, or from public or private research centers.
L'archive ouverte pluridisciplinaire HAL, est destinée au dépôt et à la diffusion de documents scientifiques de niveau recherche, publiés ou non, émanant des établissements d'enseignement et de recherche français ou étrangers, des laboratoires publics ou privés. 
Classification

Physics Abstracts

$75.50-62.20-81.40$

\title{
Tensile stress effect on magnetic properties of $\mathrm{cw}$-laser annealed amorphous $\mathrm{Fe}_{40} \mathrm{Ni}_{40} \mathbf{P}_{14} B_{6}$ ribbons
}

\author{
L. Lanotte \\ Istituto di Fisica della Facoltà di Ingegneria, Università di Napoli, \\ piazzale V. Tecchio, 80125 Napoli, Italy
}

(Reçu le 21 février 1983, révisé le 11 avril, accepté le 16 mai 1983)

\begin{abstract}
Résumé. - Nous avons mesuré la perméabilité magnétique initiale d'échantillons de metglass 2826 (ruban de $50 \mu \mathrm{m}$ d'épaisseur), recuits par laser continu, en fonction de la contrainte de tension appliquée. Les résultats montrent qu'une tension convenable peut réduire l'aimantation à très faible champ. Les courbes de magnétostriction et la variation de l'amplitude de l'onde magnétoélastique, en fonction de la tension appliquée, confirment nos prévisions. Sur la base de la compréhension actuelle du mode inhomogène de déformation, nous proposons une explication des effets observés.

Abstract. - Measurements of the initial permeability as a function of tensile stress were performed in cw-laser annealed metglas 2826 (50 $\mu \mathrm{m}$ ribbon). The results indicate the possibility of decreasing the magnetization at a very low field by means of an appropriate applied tension. The dependence of the magnetostriction curves and the magnetoelastic wave amplitude on the tensile stress supplies experimental evidence of the above mentioned prediction. On the basis of current understanding of the inhomogeneous mode of deformation, an explanation of the observed effects is proposed.
\end{abstract}

\section{Introduction.}

Thermal annealing of glassy metals has received considerable attention for understanding the amorphous-crystalline transition [1-5] and thermal stability [6-10], as well as for its influence on both mechanical and magnetic properties [11-16]. The heating was realized by means of several techniques : isothermal annealing $[17,18]$; radio frequency heat treatment $[19,20]$; annealing by magnetic field [21-24] and/or under mechanical stress [25].

Recently [26-28] it has been shown that besides the well-known stress relaxation [29, 30], the heat treatment can also produce topological changes in the amorphous structure. In particular, the effect of these variations (also caused by an applied tensile stress) on the initial permeability is opposite to that produced by the above mentioned stress relaxation which occurs at the first stage of the annealing process.

The present paper reports on the inference of such a behaviour revealed in metglas 2826, after annealing by a cw-laser. The effect of this thermal treatment on the material properties dealt with in a preceding paper [31] is comparable with that produced by conventional heating techniques. On the other hand, we shall see that laser annealing may influence the creation of stress centres within the material. In particular, the presence of these stress sites is interpreted as the source of low field magnetization decrease due to proper mechanical tension. 


\section{Experimental.}

All the measurements were performed on ribbons of $\mathrm{Fe}_{40} \mathrm{Ni}_{40} \mathrm{P}_{14} \mathrm{~B}_{6}, 30.0 \times 0.20 \times 0.005 \mathrm{~cm}^{3}$, annealed by means of a $\mathrm{CO}_{2}$ laser. As shown in reference [31], it is possible to realize a uniform heating by a continuous wave irradiation. In the present paper the evaluation of the temperature maxima was performed by means of a theoretical analysis [32] more exact than that previously used [31]. The interaction time was fixed at $0.5 \mathrm{~s}$, while the power values (of the equivalent Gaussian beam [31]) were $20 \mathrm{~W}, 40 \mathrm{~W}$ and $80 \mathrm{~W}$. Thus, during the annealing treatment, the temperature maxima was $401 \mathrm{~K}, 529 \mathrm{~K}$ and $785 \mathrm{~K}$ respectively. The laser irradiation was performed on the samples without preliminary treatments, and in all the present experiments both the magnetic field and the external tensile stress were oriented along the longitudinal ribbon axis.

In the first set of measurements concerning the initial permeability $\mu_{\mathrm{i}}$ and the magnetization curves, the classical balistic method was used. The variations of $\mu_{i}$ with increasing tensile stress were also measured performing a longitudinal uniform deformation $\varepsilon$ in the samples and calculating the relative tension $\sigma$ by the relation $\sigma=E \varepsilon$. The value of Young's modulus, $E$, was obtained from the fundamental resonance frequencies of longitudinal magnetoelastic waves produced by reversible magnetostriction and revealed by the experimental apparatus described in a previous paper [33]. The change of $E$ produced by the laser annealing was taken into account (see Ref. 31, Fig. 7); while the $\Delta E$ effect turned out to be negligible in the region of low field values to which we shall refer in the following. The same instrument arrangement used for the $E$ measurements was also employed in measuring the magnetoelastic wave amplitude as a function of $\sigma$.

\section{Results and discussion.}

The results of figure 1 indicate a decreasing of the initial permeability, $\mu_{\mathrm{i}}$, produced by a tension higher than $\sigma^{*}=0.9 \mathrm{MPa}$ in the laser annealed samples. A similar behaviour was recently revealed [28] in $\mathrm{Fe}_{60} \mathrm{Ni}_{20} \mathrm{~B}_{20}$ after a suitable combination of annealing and a subsequent applied tension. The $\mu_{\mathrm{i}}$ mentioned behaviour is validated by the results of figure 2 . In fact, for applied tension $\sigma>\sigma^{*}$ and a magnetic field value $H<H^{*} \simeq 7 \times 10^{-2} \mathrm{Oe}$, the magnetization of the annealed samples decreases with $\sigma$. One notices that the stress sensitivity is lowered by laser heating at temperature higher than $650 \mathrm{~K}$ (Fig. 3) because crystallization starts to occur.

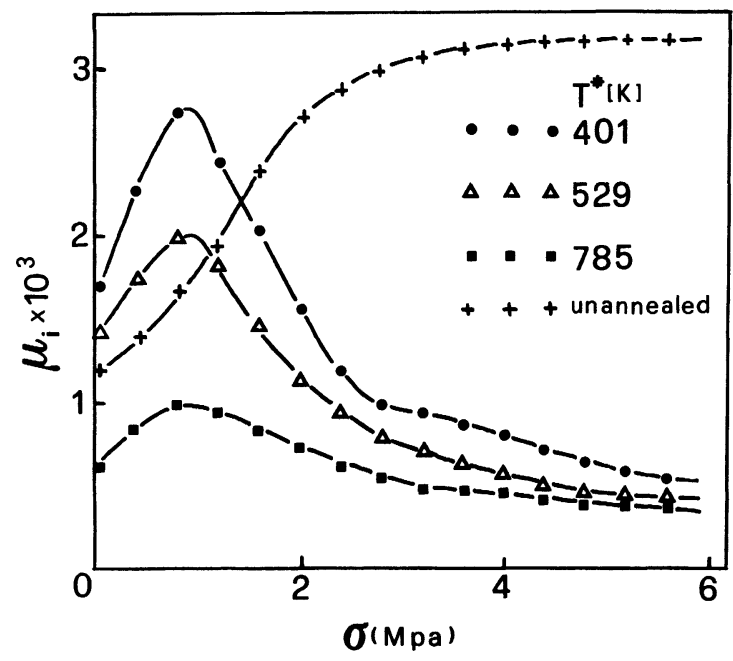

Fig. 1. - The initial permeability, $\mu_{\mathrm{i}}$, as a function of both the applied tensile stress, $\sigma$, and the maximum annealing temperature, $T^{*}$. 


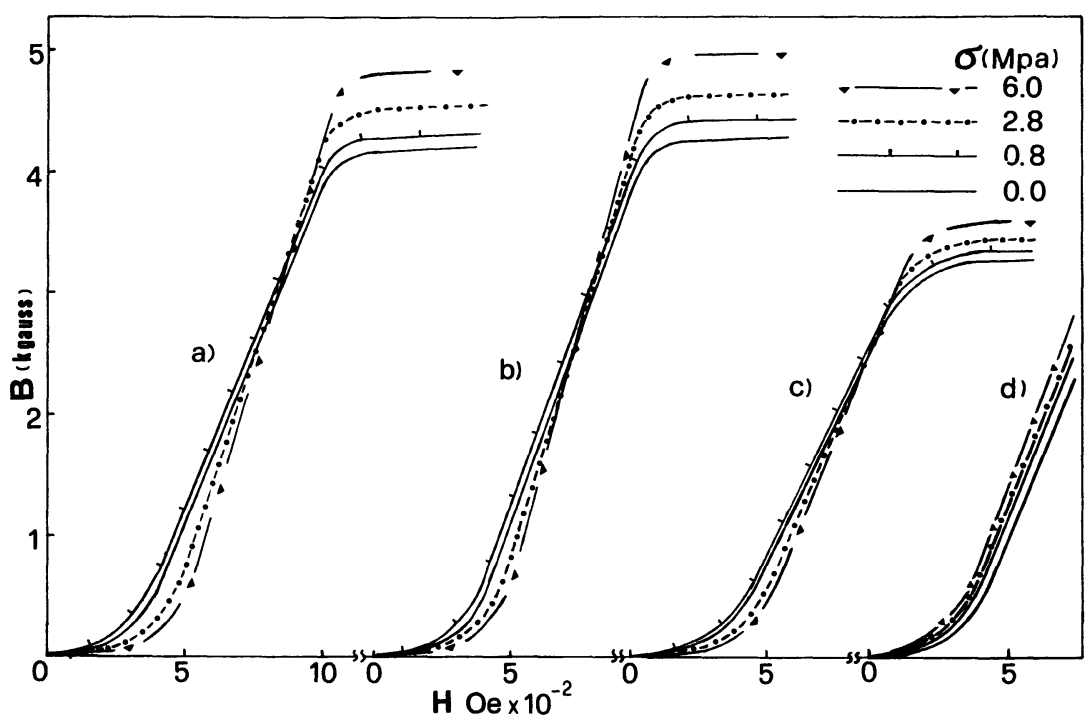

Fig. 2. - The dependence of magnetic induction on the external stress in samples heated at $T^{*}=401 \mathrm{~K}$, $(a) ; 529 \mathrm{~K}(b) ; 785 \mathrm{~K}(c)$; and in an unannealed sample $(d)$.

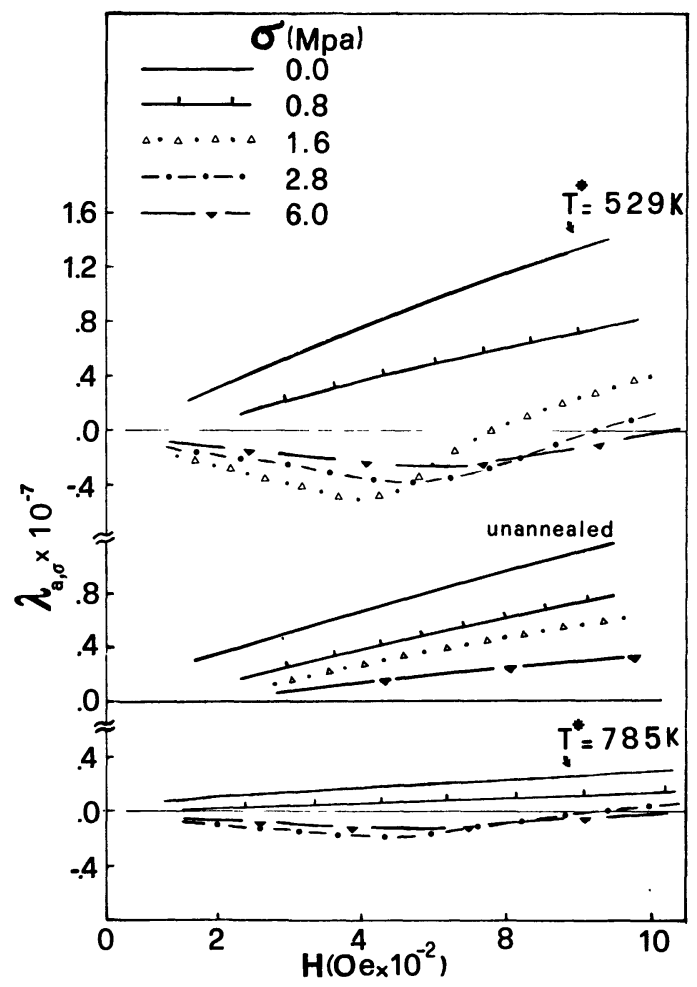

Fig. 3. - Magnetostriction curves for several values of the applied tension in heat treated samples and in a 2826 metglas ribbon as supplied by the Allied Chemical Corporation (Morristown, N. J.). 
The effects of stress on magnetization is clearly revealed by the magnetostriction behaviour as a function of $H$ and $\sigma$. The curves of figure 3 were obtained using the same method first adopted by Gonda [36]. In particular, for fixed values $H=i \Delta H$, with $\Delta H=2 \times 10^{-3}$ Oe and $i=1,2, \ldots, 60$, the variations of the magnetic induction $\Delta B_{i}$ produced by a small increase of the tension were measured. By taking into account the relation $l / l_{0} \cdot(\mathrm{d} l / \mathrm{d} H)_{\sigma}=(\mathrm{d} B / \mathrm{d} \sigma)_{H}$, where $l_{0}$ is the length of the unstressed ribbons, the magnetostriction was calculated as $\lambda(H)=\int_{0}^{H} \mathrm{~d} \lambda \simeq \sum_{i=1}^{n}\left(\Delta B_{i} / \Delta \sigma\right) \cdot \Delta H$. To distinguish the magnetostriction measured in laser annealed and stressed samples from the magnetostriction of the pure amorphous material, we denote the first one by $\lambda_{\mathrm{a}, \sigma}$.

By inspection of the curves of figure 3 it is clear that, for $\sigma>\sigma^{*}, \lambda_{\mathrm{a}, \sigma}$ is always positive, while if $\sigma<\sigma^{*}$ the sign of $\lambda_{\mathrm{a}, \sigma}$ is negative at very low field values.

A direct consequence of these magnetostrictive properties is found when the amplitude, $A$, of the magnetoelastic waves is studied. In fact $A$ is proportional to $\left|(\Delta B / \Delta \sigma)_{H}\right|$, which in turn is related to $\lambda_{\mathrm{a}, \sigma}$ by the equation quoted above. Thus, the incremental ratio $\left|\left(\Delta \lambda_{\mathrm{a}, \sigma} / \Delta H\right)_{\sigma}\right|$ gives both the value of the reversible magnetomechanical permeability [33] and a relative measure of the magnetoelastic wave amplitude $A$. On the other hand, the value of $\left|\left(\Delta \lambda_{\mathrm{a}, \sigma} / \Delta H\right)_{\sigma}\right|$ can be estimated from the derivatives of the curves of figure 3 ; so, for fixed $H \simeq 5 \times 10^{-2} \mathrm{Oe}$, it is deduced that the behaviour of $A$ versus $\sigma$ should present a relative maximum for $\sigma \simeq \sigma^{*}$. This prediction was verified by the direct measurements of $A$ as shown in figure 4.

The experimentally revealed behaviour of $\mu_{\mathrm{i}}, M, \lambda$ and $A$ in the pure metglas ribbons(Figs. 1, 2d, $3,4)$ are very different from those measured in the heated samples. For example, in agreement with the results of previous measurements [34,35], the magnetostriction was positive also for $\sigma$ values higher than $\sigma^{*}$. Thus, it appears that the laser annealing alters, to some extent, the microstructure thereby producing changes in the response to an external tension.

A possible interpretation of the effects caused by a tensile stress higher than $\sigma^{*}$ can be based on inhomogeneous deformation models already developed which stem from the presence of free volume in the amorphous matrix [37]. In other words, in some regions, the activation energy required for the atomic rearrangement is low; it is just here that the dilatation can lead to a plastic deformation and stress centres [38]. If this happens, the process of initial magnetization

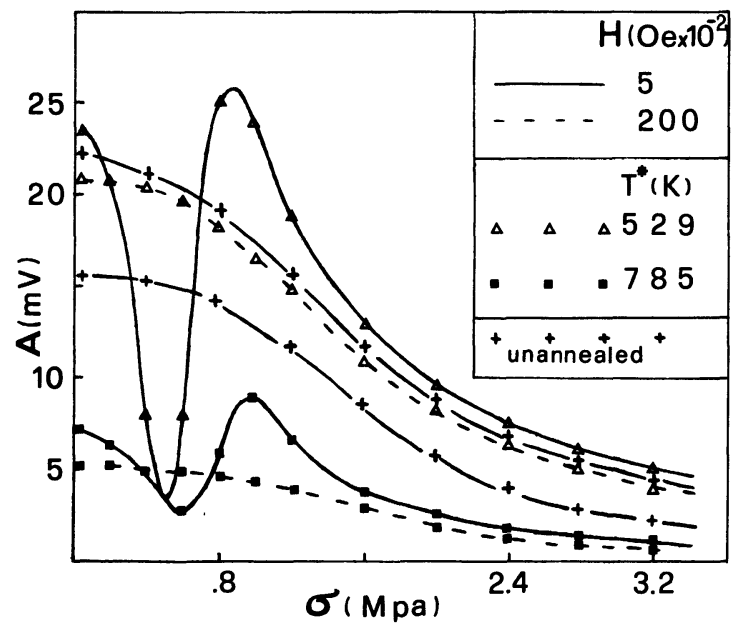

Fig. 4. - The magnetoelastic wave amplitude versus the tensile stress in annealed samples, at low magnetic field (full lines) and at saturation (dashed lines), compared to the $A$ values measured in the pure material. 
proceeds with great difficulty and consequently $\mu_{\mathrm{i}}$ decreases. This assumption is confirmed by recent results [39] which agree with a model where the obstacles, opposing to the domain wall displacement in magnetostrictive materials, are represented by elastic stress centres.

In order to verify the qualitative interpretation, a further investigation was performed which validates the possibility of obtaining stress driven topological changes in the used ribbons. In these measurements, a tensile stress was applied and subsequently removed. Figure 5 shows that, if $\sigma$ was lower than $\sigma^{*}, \mu_{i}^{*}$ (the initial permeability after $\sigma$ removal) does not vary; on the other hand, when $\sigma$ exceeds $\sigma^{*}$, as a consequence of the stress treatment, the $\mu_{i}^{*}$ values decrease. This fact can be ascribed to the rearrangement of the atomic distribution mentioned above, which only occurs when a high tension is applied. It is worth noting that, when the unstressed conditions are reproduced, the low field magnetization is increased by a slight tension although the samples were subjected to a very high tensile stress. Thus, one can argue that, only in the presence of a bias $\sigma>\sigma^{*}$, a tension increase, $\Delta \sigma$, is able to decrease the low field magnetization.

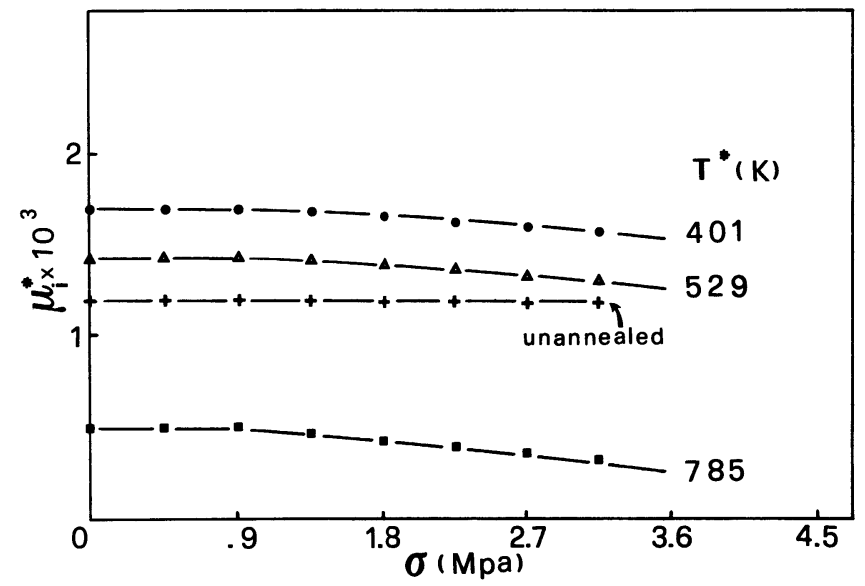

Fig. 5. - The initial permeability values, $\mu_{i}^{*}$, measured in the demagnetized state after applied tension removal.

\section{Conclusion.}

The previous data [31] and the results presented here lead to the conclusion that the relaxation of the quenching stresses is realized by means of the $\mathrm{cw}$-laser treatment for temperatures well below the crystallization value $\left(T_{\text {cryst. }} \simeq 650 \mathrm{~K}\right)$. This fact is validated by the increase of both the magnetostriction and the saturation magnetization. At the same time the cw-laser annealing probably creates small defects which became the sites of local stress anisotropically oriented under the application of an external tension. This hypothesis is based on the fact that the laser annealing subjects the samples to a very large variation of temperature in a very short time $(200 \mathrm{~K} / 0.2 \mathrm{~s})$. The dilatation, occurring during the rapid increase of the temperature shrinks the agglomerate of free volume already present in the material, but, on the other hand, the rapid cooling can produce inhomogeneity of local density. In other words, after the laser heating, it could be assumed that the number of vacancies increases although the excess volume will be better distributed. Since irreversible effects are induced by a large stress value, the magnetic anisotropy caused by the laser annealing and the subsequently applied tension, should derive from the contributions of anelastic and plastic deformation [40]. In order to have a clearer picture of the situation and to distinguish the above mentioned contributions, further experiments are in progress. 


\section{Acknowledgments.}

The author is very grateful to Profs. F. Porreca and C. Luponio for providing facilities and for encouragement and useful suggestions. The performance of the laser treatment by Dr. V. Tagliaferri and the RTM Institute (Torino-Italy) is warmly acknowledged.

\section{References}

[1] Wolfram, T. and Hall, W., Phys. Rev. 143 (1966) 284.

[2] Hasegawa, R. H., Argyle, B. E. and Tao, L. J., AIP Conf. Proc. 24 (1975) 110.

[3] McColl, J. R., Murphy, D., Cargill iI, G. S. and Mizoguchi, T., AIP Conf. Proc. 29 (1976) 172.

[4] Narika, K., Yamasaki, J. and Fukumaga, H., IEEE Trans. Magn. 13 (1977) 1544.

[5] Potocky, L., Novak, L. and Kisoli-Kaszo, E., Acta Phys. Slov. 29 (1979) 281.

[6] Kikuchi, M., Fujimori, H., OHI, Y, and Masumoto, T., Japan J. Appl. Phys. 14 (1974) 1889.

[7] Chen, H. S., Ferris, S. D., Gyorgy, E. M., Leamy, H. J. and Sherwood, R. C., Appl. Phys. Lett. 26 (1975) 405.

[8] ScotT, M. G., J. Mat. Sci. 13 (1978) 291.

[9] Buschow, K. H. J., J. Physique Colloq. 41 (1980) C8-559.

[10] Warlimont, H. and Boll, R., J. Magn. Magn. Mat. 26 (1982) 97.

[11] Graham Jr., C. D., Egami, T., Williams, R. S. and Takei, Y., AIP Conf. Proc. 29 (1975) 216.

[12] Egami, T., Mater. Res. Bull. 13 (1978) 557.

[13] Barbee, T. W., Holmes, W. H., Keith, D. L., Pyzy, M. K. and Ilonea, G., Thin Solid Films 45 (1977) 591.

[14] Potocky, L., Zentko, A., Novak, L. and Duhaj, P., J. Magn. Magn. Mat. 18 (1980) 147.

[15] Cecchetti, A., Masoli, F., Poppi, M. and Soardo, G. P., J. Magn. Magn. Mat. 19 (1980) 284.

[16] Allia, P., Mazzetti, P., Soardo, G. P. and Vinai, F., J. Magn. Magn. Mat. 15-18 (1980) 1361.

[17] Girt, E., Tomic, P., Kursumovic, A. and Mihac-Kosanovic, T., J. Physique Colloq. 41 (1980) C8-875.

[18] Morris, D. G., Acta Met. 29 (1981) 1213.

[19] LuborsKy, F. E., Mater. Sci. Eng. 28 (1977) 139.

[20] KopCeWICZ, M., Appl. Phys. 23 (1980) 1.

[21] LubORSKy, F. E., BeCKER, J. J. and MCCARY, R. O., IEEE Trans. Magn. 11 (1975) 1644.

[22] LuborSKy, F. E. and WALTER, J. L., Mater. Sci. Eng. 28 (1977) 77.

[23] Pfeifer, F. and Behnke, W., J. Magn. Magn. Mat. 6 (1980) 80.

[24] Gangulle, A., Aboaf, J. A. and Kobliska, R. J., J. Appl. Phys. 52 (1981) 2928.

[25] Egami, T., Flanders, P. J. and Graham Jr., C. D., AIP Conf. Proc. 24 (1975) 697.

[26] Gibis, M. R. J., EvetTs, J. E. and Shah, N. J., J. Appl. Phys. 50 (1979) 7642.

[27] Neite, G. and Nembach, E., J. Magn. Magn. Mat. 26 (1982) 133.

[28] Potocky, L., Zentko, A., Novak, L., Svidron, V. and DuhaJ, P., J. Magn. Magn. Mat. 26 (1982) 115.

[29] Liebermann, H. H., Graham Jr., C. D. and Flanders, P. J., IEEE Trans. Magn. 13 (1977) 1541.

[30] Egami, T., J. Mater. Sci. 13 (1978) 2587.

[31] Lanotte, L., Luponio, C., Porreca, F. and Tagliaferri, V., Nuovo Cimento D 6 (1982) 802.

[32] Lanotte, L. and TAgliaferri, V., Proc. 3rd Intern. Colloquium on Welding and Melting by Electrons and Laser Beam, Lyon France (1983) to be published.

[33] Lanotte, L., Luponio, C. and Porreca, F., J. Appl. Phys. (1979) 438.

[34] Egami, T., Flanders, P. J. and Graham Jr., C. D., AIP Conf. Proc. (1975) 697.

[35] ARoca, C., SANCHEZ, P. S. and LopeZ, E., IEEE Trans. Magn. 17 (1981) 1462.

[36] GondA, P., J. Magn. Magn. Mat. 19 (1980) 423.

[37] GibBs, M. R. J., EvetTs, J. E. and Horton, M. E., J. Physique Colloq. 41 (1980) C8-706.

[38] Argon, A. S., Acta Met. 27 (1979) 47.

[39] Gröger, B. and Kroumüller, H., Appl. Phys. 24 (1981) 287.

[40] Nielsen, O. V., Wind Nielsen, H. J., Masumoto, T. and Kimura, H. M., J. Magn. Magn. Mat. 24 (1981) 88 . 